\title{
Preliminary Seroepidemiological Investigation Regarding Mycobacterium Avium Infection in Wild Boars and Foxes
}

\author{
Ioana Alexandra RĂȚOI ${ }^{1 *}$, Luciana Alexandra CRIVEI ${ }^{1}$, Daniela POREA ${ }^{2}$, Anca Mihaela DASCĂLU ${ }^{1}$, \\ Andreea Paula COZMA ${ }^{1}$, Luanda Elena OȘLOBANU ${ }^{1}$, Dragoș Constantin ANIȚA ${ }^{1}$, Adriana ANIȚA ${ }^{1}$, \\ Gheorghe SAVUȚA ${ }^{1}$ \\ ${ }^{1}$ Department of Public Health. The University of Agricultural Sciences and Veterinary Medicine Iasi, \\ Romania. \\ ${ }^{2}$ Centre for the Study of Transborder and Emergent Diseases and Zoonoses Department, Danube Delta \\ National Institute for Research and Development, Tulcea, Romania \\ ${ }^{*}$ Corresponding author: ioana.anton10@yahoo.com
}

Bulletin UASVM Veterinary Medicine 77(2)/2020

Print ISSN 1843-5270; Electronic ISSN 1843-5378

doi:10.15835/buasvmcn-vm:2020.0010

\begin{abstract}
The present study aimed at identifying Mycobacterium avium seroprevalence in wild boars (Sus scrofa) and red foxes (Vulpes vulpes) samples, from the Eastern region of Romania, by using an indirect ELISA assay. A total of 367 wild animal samples were collected from eight counties: 275 wild boars sera samples from Iasi ( $\mathrm{n}=209)$, Botosani ( $\mathrm{n}=11)$, Bacau ( $\mathrm{n}=17)$, Galati $(\mathrm{n}=27)$ and Covasna $(\mathrm{n}=11)$ and 92 fox samples of thoracic fluid from Iasi $(\mathrm{n}=30)$, Suceava $(\mathrm{n}=20)$, Neamt $(\mathrm{n}=19)$, Vaslui $(\mathrm{n}=11)$ and Galati $(\mathrm{n}=12)$. Specific antibodies were not detected in wild boar serum samples tested. From the fox samples, one was positive (1.08\%), originating from Galati County. Our results may be correlated with a reduced distribution of Mycobacterium avium subspecies in the environment and a low prevalence of infections caused by these bacteria in wild animals. The current assessment shows that foxes have a limited role in the epidemiology of nontuberculous mycobacterial infections.
\end{abstract}

Keywords: Mycobacterium avium, seroprevalence, wildlife

\section{Introduction}

Infections caused by nontuberculous mycobacteria (NTM) of the Mycobacterium avium Complex (MAC) were reported in various domestic or wild species, ruminant, omnivorous or carnivorous. MAC members, most notably Mycobacterium avium subsp. paratuberculosis (MAP) and Mycobacterium avium subsp. avium (MAA), are the most commonly reported species, causing in some wildlife species similar lesion aspects to those encountered in domestic animals (Thorel et al., 2001).

Evidence of natural infection with MAC members in wild animals is provided by studies conducted in various countries as Scotland (Beard et al., 2001), Spain (Boadella et al., 2011), Portugal (Matos et al., 2015) or Norway (Tryland et al., 2004). The wild boars (Sus scrofa) are amongst the species with a large territorial distribution in Europe. NTM infection and dissemination can be possible in wild boars, considering the species adaptability to environmental changes and the ability to cross natural barriers, the omnivorous diet, the contact with many other wild and domestic animal species and the wide distribution (Boadella et al., 2011). Numerous studies have highlighted the role of feral pigs in maintaining and spreading 
mycobacteria from MAC and Mycobacterium bovis (Trcka et al., 2008; Naranjo et al., 2008, Richomme et al., 2019). The lesions are rarely observed, more frequently in adult animals and are usually present in the lymph nodes. MAC infections in carnivores are most often localized at the digestive tract and occur as a result of ingestion of the bacilli during feeding, environmental contamination being unlikely. Small rodents, birds and rabbits included in fox diet are the most likely the source of infection.

Determining the prevalence of nontuberculous mycobacterial infections among wild animal populations provides significant additional information on the distribution and transmission of these infections. In the context of a common habitat, where there may be interactions between cattle and wild animals and taking into account the opportunistic infectious capacity of the NTM, their resistance in the environment and the possibility of developing a sensitisation to tuberculin condition in cattle, information regarding the epidemiology of NTM infection in wildlife is of valuable use in assessment of the tuberculosis control program efficiency. Furthermore, the evaluation of the health status of wild animal populations should not be neglected.

To our knowledge, no serological investigations have been carried out so far regarding infections with MAC members in wild animals, in Romania.
The purpose of this study was to conduct a seroprevalence study regarding the presence of anti-MAC antibodies in wild boars and wild foxes, from seven counties located in Eastern Romania and one in the central region of the country.

\section{Materials and methods}

In this study, 275 randomly collected wild boar sera samples from the following counties in Eastern Romania were tested: Iasi $(n=209)$, Botosani ( $n=11)$, Bacau $(n=17)$, Galati $(n=27)$, along with eleven samples from Covasna County. Sampling was performed during the 2017-2018 hunting seasons, sera being stored at $-20^{\circ} \mathrm{C}$, until the time of testing. Age, gender and the origin hunting fund of wild boars from Iasi County are presented in Table 1. These data were not available for the wild boars in the other counties.

In addition, 92 samples of thoracic fluids from wild foxes (Vulpes vulpes) were tested. Fox samples were collected during 2015, after rabies vaccination campaign and previously tested for effectiveness of oral rabies vaccinations. The study included fox samples originated from five counties in N-E area of Romania (Figure 1).

For the identification of anti-Mycobacterium avium IgG antibodies in serum samples and thoracic fluids, an indirect ELISA commercial kit was used (ID Screen ${ }^{\circledR}$ Mycobacterium avium Indirect Multispecies, ID.vet, Innovate Diagnostics, France).

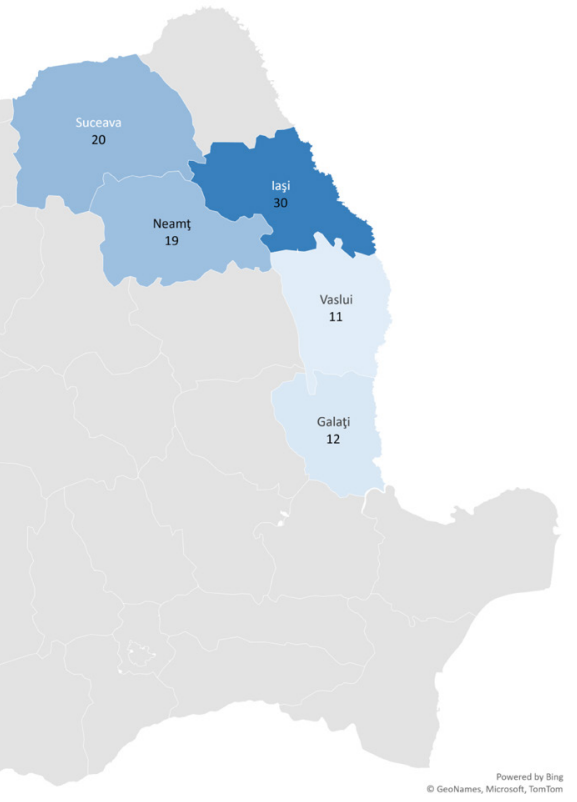

Figure 1. Geographic origin of the fox samples 
Table 1. Data regarding the distribution and origin of the samples from Iași County

\begin{tabular}{|c|c|c|c|c|c|c|}
\hline \multirow{2}{*}{ Hunting fund (HF) } & \multirow{2}{*}{$\begin{array}{l}\text { Number of tested } \\
\text { samples / funds }\end{array}$} & \multicolumn{2}{|c|}{ Gender } & \multicolumn{3}{|c|}{ Age category } \\
\hline & & $\mathbf{M}$ & $\mathbf{F}$ & Yearling & Juvenile & Adult \\
\hline 1 Tatarusi & 1 & & 1 & & & 1 \\
\hline 2 Motca & 2 & & 2 & & & 2 \\
\hline 3 Miroslovesti & 2 & 2 & & & & 2 \\
\hline 4 Halaucesti & 1 & & 1 & & & 1 \\
\hline 5 Stolniceni Prajescu & 4 & & 4 & & & 4 \\
\hline 6 Stroesti & 1 & 1 & & & 1 & \\
\hline 7 Harmanesti & 1 & 1 & & & & 1 \\
\hline 8 Siretel & 2 & 2 & & & & 2 \\
\hline 9 Bahlui & 24 & 8 & 16 & & 8 & 16 \\
\hline 10 Catalina & 3 & 2 & 1 & 2 & & 1 \\
\hline 17 Gropnita & 1 & 1 & & & & 1 \\
\hline 22 Turia Perieni & 23 & 11 & 12 & & 6 & 17 \\
\hline 23 Larga Jijia & 2 & 1 & 1 & & & 2 \\
\hline 24 Probota & 3 & 2 & 1 & & & 3 \\
\hline 25 Letcani & 2 & 2 & & & & 2 \\
\hline 27 Victoria & 8 & 4 & 4 & & 1 & 7 \\
\hline 28 Golaesti & 3 & 2 & 1 & 1 & & 2 \\
\hline 29 Tutora & 2 & 2 & & & & 2 \\
\hline 30 Prisacani & 4 & 4 & & & & 4 \\
\hline 31 Strunga & 3 & 3 & & & & 3 \\
\hline 32 Crivesti & 5 & 3 & 2 & & 4 & 1 \\
\hline 33 Braiesti & 6 & 2 & 4 & & & 6 \\
\hline 35 Sinesti & 4 & & 4 & 4 & & \\
\hline 37 Gheorghitoaia & 8 & 8 & & & 3 & 5 \\
\hline 38 Horlesti & 4 & 2 & 2 & 2 & & 2 \\
\hline 40 Mogosesti & 7 & 2 & 5 & 1 & 2 & 4 \\
\hline 41 Barnova & 1 & 1 & & & & 1 \\
\hline 42 Poieni & 14 & 4 & 10 & 1 & 3 & 10 \\
\hline 43 Schitu Duca & 4 & 2 & 2 & & 2 & 2 \\
\hline 44 Pietrosu & 7 & 1 & 6 & & 3 & 4 \\
\hline 45 Pocreaca & 2 & 1 & 1 & & & 2 \\
\hline 46 Bradicesti & 3 & & 3 & & 3 & \\
\hline 47 Bunesti & 2 & 1 & 1 & & 1 & 1 \\
\hline 48 Crasnita & 14 & 11 & 3 & 1 & 2 & 11 \\
\hline 49 Gorban & 4 & 3 & 1 & & 1 & 3 \\
\hline 50 Raducaneni & 7 & 5 & 2 & & & 7 \\
\hline 51 Grajduri & 16 & 11 & 5 & & 3 & 13 \\
\hline 52 Mironeasa & 4 & 1 & 3 & & 2 & 2 \\
\hline 53 Tibana & 1 & 1 & & & 1 & \\
\hline 54 Tibănesti & 4 & 2 & 2 & & 2 & 2 \\
\hline
\end{tabular}


Sample testing was performed according to the manufacturer's specifications. The test presents a wide applicability, not only to detect the circulation of Mycobacterium avium subsp. hominissuis at herd level, in domestic pigs, but can also be used on serum and plasma samples from a variety of domestic (sheep, goats, cattle and pigs) and wild animals. According to the values provided by the manufacturer and preliminary studies (Lesceu and Pourquier, 2011; Eisenberg et al., 2012), the used ELISA method presents a sensitivity ranging from $34.48 \%$ to $44 \%$ and a specificity of $100 \%$.

The plates were read at $450 \mathrm{~nm}$ wavelength, using the ELISA Sunrise ${ }^{\mathrm{TM}}$ Absorbance Reader (Tecan Group Ltd., Männedorf, Switzerland). The evaluation of the obtained results was performed according to the protocol formulas, samples being considered negative if the Cut-off was lower than $40 \%$ and positive if higher than $50 \%$. Confidence intervals were calculated using the online platform VassarStats: Website for Statistical Computation (http://vassarstats.net/).

\section{Results and discussions}

Following the serological testing of the 275 wild boar sera, with the use of a commercial indirect ELISA kit, no anti-Mycobacterium avium antibodies were detected in evaluated serum samples. As such, no correlation could had been made with gender and age. Only one fox sample from Galati County was detected positive $(1.08 \%$, CI 95\%: 0,1\% - 5.9\%) for Mycobacterium avium antibodies.

Amongst MAC members, MAP is the nontuberculous mycobacteria with the greatest negative impact on animal welfare. The importance of wildlife in paratuberculosis transmission is so far recognized (Stevenson et al., 2009), the aetiological agent being isolated from different wild species, including Suidae -wild boars and Canidae -foxes (EFSA AHAW Panel, 2017).

Wild boars are known to be relevant reservoirs for Mycobacterium bovis in the Iberian Peninsula (Aranaz et al., 2004, Boadella et al., 2011), especially in Spain, where game-management practices are common (Naranjo et al., 2008). Moreover, tuberculous mycobacteria were isolated from this species in other European countries also and depending on the epidemiological context, wild boars may act as spill-over hosts, maintenance hosts or super-shedders for bovine tuberculosis (Richomme et al., 2019).

Studies on MAC infection in wild boar populations are quite a few. The wild boar is an omnivore which, in the wild, occasionally feeds on small animals and birds, such as rabbits (Lepus europeus), pheasants (Ithaginis spp.), partridges (Perdix perdix) or young ruminants. The wild boar also feeds on remains of carcasses from dead wild animals or domestic animals improperly disposed of (Machackova et al., 2003). Thus, mycobacterial infection may be transmitted through both respiratory (during digging) and digestive (ingestion of debris from contaminated pastures, offal from infected dead animals) routes (Machackova et al., 2003).

In general, a low frequency of MAP is expected in wild boars, up to $5 \%$ according to the results reported by Alvarez in Spain or Machackova in various countries in central Europe (Alvarez et al., 2005, Machackova et al., 2003). Moreover, it is considered that in areas where other mycobacterial infections are prevalent, wild boars are not the most relevant marker for paratuberculosis (Carta et al., 2013). Boadella et al. (2011) evaluating the presence for MAP antibodies (PPA 3) in wild boars' sera, using an ELISA method, suggested that wild boars cannot be considered sentinels for MAC infections. MAA infection in wild boars is very difficult to detect, however Lara et al. (2011) have succeeded in isolating the mycobacteria from mesenteric and submaxillary lymph nodes.

The lack of seroconversion revealed by this study could be explained by a real low level of exposure to MAC mycobacteria. Using the same method, Matos et al. (2015) identified a prevalence of $23.9 \%$ for the wild boar tested in Portugal. Moreover, our results can be correlated with a lower number of paratuberculosis outbreaks $(n=27)$ identified between 2014-2018 in our country and reported in the World Animal Health Information System (WAHIS) portal of World Organisation for Animal Health (WOAH-OIE). Moreover, in the $\mathrm{N}$-E region of the country, only one outbreak was reported in Iasi County (1 outbreak in 2015) and two in Botosani (two outbreaks in 2016).

Garrido et al. (2010) observed that in case of MAA experimental infection in wild boars, clinical signs are absent, and lesions occur in the head and mesenteric lymph nodes at an infective dose of $2.5 \times 10^{6}$ mycobacterial cells (Garrido et 
al., 2010). These observations are reinforced by the lesions observed by other authors in natural infections (Machackova et al., 2003). In addition, it was suggested that depending on the path of infection, respiratory (in close contact with shedders) or digestive tract (consumption of infected tissues), the development of the immune response is different and may be correlated with the mycobacterial infection manifesting potential (Garrido et al., 2010).

The use of serological methods for MAC infections evaluation in wild mammals is not widely performed, making a difficult analysis of our results. Using the same testing procedure, Matos et al. (2015) identified a single positive fox sample out of 42 tested (2.4\%). MAP was isolated or identified by PCR in foxes in Europe (Beard et al., 2001, Florou et al., 2008). In Portugal, infection with MAP is common among wild carnivores (Matos et al., 2014).

Furthermore, in countries where the paratuberculosis prevalence is higher, evidence of infection is encountered in wild animal hosts. Our results may be correlated with a reduced distribution of MAC members in the environment and a low prevalence of infections caused by these bacterial agents in animals, either wild or domestic. A lack of involvement or a limited role of foxes in the epidemiology of nontuberculous mycobacterial infections is revealed from the current assessment. As in many grazing areas from the assessed counties cattle, sheep and goats are raised in extensive systems, the common interface between domestic and wildlife is created. Furthermore, as wild lagomorphs are linked to foxes and considered to pose the highest MAP transmission risk for livestock, of the nonruminant hosts, a more accurate epidemiologic situation may be revealed by extending the number of fox samples and continue the evaluation in other species, such as rabbits.

\section{Conclusions}

To the extent of our knowledge, this is the first MAC seroprevalence study conducted in our country on wild animal species. Considering the fact that serosurveys on MAC infection in wildlife are not widely performed, and only few published results are available, the comparison of our results proved to be difficult. Though negative, the serologic response identified in this study opens the research in the context of nontuberculous mycobacterial infections in wildlife, and further analysis is considered appropriate in order to observe whether in our country the mycobacterial infection shifted in wildlife direction and even if there is an underestimation in livestock.

Acknowledgments. This work was undertaken by the project team involved in the POC grant entitled: "Regional Center of Advanced Research for Emerging Diseases, Zoonoses and Food Safety - ROVETEMERG", Smis 107563.

\section{References}

1. Alvarez J, de Juan L, Briones V, Romero B, Aranaz A, Fernandez-Garayzabak JF, Mateos A (2005). Mycobacterium avium subsp. paratuberculosis in fallow deer and wild boar in Spain. Veterinary Record, 156: 212213.

2. Aranaz A, de Juan L, Montero N, Sánchez C, Galka M, Delso C, Alvarez J, Romero B, Bezos J, Vela AI, Briones V, Mateos A, Domínguez L (2004). Bovine tuberculosis (Mycobacterium bovis) in wildlife in Spain. Journal of clinical microbiology, 42(6): 2602-2608.

3. Beard PM, Daniels MJ, Henderson D, Pirie A, Rudge K, Buxton D, Rhind S, Greig A, Hutchings MR, McKendrick I, Stevenson K, Sharp JM (2001). Paratuberculosis infection of nonruminant wildlife in Scotland. Journal of clinical microbiology, 39: 1517-1521.

4. Boadella M, Lyashchenko K, Greenwald R, Esfandiari J, Jaroso R, Carta T, Garrido JM, Vicente J, de la Fuente J, Gortázar C (2011). Serologic tests for detecting antibodies against Mycobacterium bovis and Mycobacterium avium subspecies paratuberculosis in Eurasian wild boar (Sus scrofa scrofa). Journal of Veterinary Diagnostic Investigation, 23(1): 77-83.

5. Carta T, Álvarez J, Pérez de la Lastra JM, Gortázar C (2013). Wildlife and paratuberculosis: a review. Research in Veterinary Science, 94(2): 191-197.

6. EFSA AHAW Panel (EFSA Panel on Animal Health and Welfare): More S, Bøtner A, Butterworth A, Calistri P, Depner K, Edwards S, Garin-Bastuji B, Good M, Gortazar Schmidt C, Michel V, Miranda MA, Nielsen SS, Raj M, Sihvonen L, Spoolder H, Stegeman JA, Thulke H-H, Velarde A, Willeberg P, Winckler C, Baldinelli F, Broglia A, Zancanaro G, Beltran-Beck B, Kohnle L, Morgado J, Bicout D (2017). Scientific Opinion on the assessment of listing and categorisation of animal diseases within the framework of the Animal Health Law (Regulation (EU) No 2016/429): paratuberculosis. EFSA Journal, 15(7):4960, p. 47.

7. Eisenberg T, Volmer R, Eskens U, Moser I, Nesseler A, Sauerwald C, Seeger H, Klewer-Fromentin K, Möbius $P$ (2012). Outbreak of reproductive disorders and mycobacteriosis in swine associated with a single strain of Mycobacterium avium subspecies hominissuis. Veterinary microbiology, 159(1-2): 69-76. 
8. Florou M, Leontides L, Kostoulas P, Billinis C, Sofia M, Kyriazakis I, Lykotrafitis F (2008). Isolation of Mycobacterium avium subspecies paratuberculosis from non-ruminant wildlife living in the sheds and on the pastures of greek sheep and goats. Epidemiology and Infection, 136(5): 644-652.

9. Garrido JM, Vicente J, Carrasco-García R, Galindo RC, Minguijón E, Ballesteros C, Aranaz A, Romero B, Sevilla I, Juste R, de la Fuente J, Gortazar C (2010). Experimental infection of Eurasian wild boar with Mycobacterium avium subsp. avium. Veterinary microbiology, 144(1-2): $240-245$.

10. Lara GHB, Ribeiro MrG, Leite CQF, Paes AC, Guazzelli A, Silva AVd, Santos ACB, Listoni FJP (2011). Occurrence of Mycobacterium spp. and other pathogens in lymph nodes of slaughtered swine and wild boars (Sus scrofa). Research in Veterinary Science, 90(2): 185-188.

11. Machackova M, Matlova L, Lamka J, Smolik J, Melicharek I, Hanzlikova M, Docekal J, Cvetnic Z, Nagy G, Lipiec M, Ocepek M, Pavlik I (2003). Wild boar (Sus scrofa) as a possible vector of mycobacterial infections: reviews of literature and critical analysis of data from Central Europe between 1983 to 2001. Veterinarni Medicina, 48: 51-65.

12. Matos A, Figueira L, Matos M, Pinto M, Coelho A (2015). Seroprevalence of Mycobacterium avium complex in wild mammals in the Iberian Peninsula. Journal of the Hellenic Veterinary Medical Society, 66(3): 177-184.

13. Matos AC, Figueira L, Martins MH, Loureiro F, Pinto ML, Matos M, Coelho AC (2014). Survey of Mycobacterium avium subspecies paratuberculosis in Road Killed Wild Carnivores in Portugal. Journal of Zoo and Wildlife Medicine, 45: 775-781.

14. Naranjo V, Gortazar C, Vicente J, de la Fuente J (2008) Evidence of the role of European wild boar as a reservoir of Mycobacterium tuberculosis complex. Veterinary microbiology, $127(1-2):$ 1-9.

15. Pourquier P, Lesceu S (2011). Preliminary validation of the ID Screen $\AA$ Mycobacterium avium Multispecies Indirect ELISA. Poster presented at the AHVLA International Conference 2011, Animal Diseases and their Consequences, Royal Holloway, England.

16. Richomme C, Courcoul A, Moyen JL, Reveillaud É, Maestrini O, de Cruz K, Drapeau A, Boschiroli ML (2019). Tuberculosis in the wild boar: Frequentist and Bayesian estimations of diagnostic test parameters when Mycobacterium bovis is present in wild boars but at low prevalence. PloS One, 14(9): e0222661.

17. Stevenson K, Àlvarez J, Bakker D, Biet F, de Juan L, Denham S, Dimareli Z, Dohmann K, Gerlach GF, Heron I, Kopecna M, May L, Pavlik I, Sharp JM, Thibault VC, Willemsen P, Zadoks R, Greig A (2009). Occurrence of Mycobacterium avium subspecies paratuberculosis across host species and European countries with evidence for transmission between wildlife and domestic ruminants. BMC microbiology, 9: 212.

18. Thorel MF, Huchzermeyer HF, Michel AL (2001). Mycobacterium avium and Mycobacterium intracellulare infection in mammals. Revue scientifique et technique (International Office of Epizootics), 20(1): 204-218.

19. Trcka I, Lamka J, Suchy R, Kopecna M, Beran V, Moravkova M, Horvathova A, Bartos M, Parmova I, Pavlik I (2006). Mycobacterial infections in European wild boar (Sus scrofa) in the Czech Republic during the years 2002 to 2005. Veterinarni Medicina, 51: 320-332.

20. Tryland M, Olsen I, Vikøren T, Handeland K, Arnemo JM, Tharaldsen J, Josefsen TD, Reitan LJ (2004). Serologic survey for antibodies against Mycobacterium avium subsp. paratuberculosis in free-ranging cervids from Norway. Journal of Wildlife Diseases, 40(1): 32-41. 